\title{
8 Concrete Does not Cry: Interdisciplinary Reflections on and Beyond Housing
}

Here they are, ready to talk to us: two young professionals, an architect and a civil engineer, who go well beyond established boundaries of their disciplinary backgrounds. They reach out, experiment, and innovate. The focus of their work: end users, beneficiaries, dwellers, inhabitants, simply people. Both include the human element into professional fields primarily dominated by technical details, figures, and formulas. Although the importance and contribution of social disciplines to their fields are yet to be recognized, they concentrate on the importance of human interaction, communication, and community. Out of personal interest and professional curiosity, they apply interdisciplinary research methods. They go against the flow, visit archives to learn more about the history of the construction environment in their own countries. Or they include elements of self-reflection into architecture classes after a field trip to South Africa with students.

The idea behind this contribution arose out of a perceived need to balance the academic chapters in this book with a more practice-based, practical approach. We wanted to integrate the richness of observation of those who spend most of their time on construction sites rather than in archives or libraries. Nevertheless, academia is not at all foreign to our interviewees. Both authors professionally ended up where they are now by mere coincidence. Nicholas Sungura is a Kenyan civil engineer, with professional experience gained while working for a public institution mandated with infrastructure development in his country. Dreaming once of a career as a medical doctor, engineering turned out to be only his second choice. He concluded his doctoral research on risk management in public infrastructure projects at the Leibniz University of Hannover and currently works in Germany as a risk manager for a leading railway service provider. Marlene Wagner is an Austrian architect who has spent a great deal of her professional career implementing design-build projects in South Africa, also more or less by coincidence. She is a co-founder of a successful NGO called buildCollective and works as a part-time lecturer at a number of universities. Both left their known/familiar surroundings to develop their professional potential and skills abroad. 


\section{MARLENE WAGNER}

- Born: 1981 in Klagenfurt, Austria

- Education: MA Architecture, Vienna University of Technology, 2010

- Special interest in: social architecture, design-build, non-formal spatial practices, alternative urban and architectural production

- Currently: founding member of NGO buildCollective for architecture and development; project assistant and PhD student at Vienna University of Technology, external lecturer at the University of Applied Sciences, FH Campus Wien, Kunstuniversität Linz

- Previously: external lecturer, Carinthia University of Applied Sciences, University of the Witwatersrand, Vienna University of Technology

\section{NICHOLAS SUNGURA}

- Born: 1978 in Nairobi, Kenya

- Education: Dr. Eng. Civil Engineering, Leibniz University of Hannover, 2016

- Special interest in: human element, risk management, public infrastructure, historical perspectives

- Currently: risk manager of rail infrastructure projects of a leading railway service provider in Germany

- Previously: civil engineer in a public institution mandated with infrastructure development in Kenya

For this publication, they shared their visions and views with us. We spoke about professional experiences, interdisciplinary approaches, and the contribution of architects and civil engineers to the study of housing. We thereby touched upon the complexity of construction projects, as well as recurring challenges and failures. Some of the questions asked were identical, while others were specifically tailored to their experiences. Although the two interviewees do not know each other, and the interviews took place at separate locations at different times, ${ }^{1}$ their answers contain many commonalities. The following pages offer an insight into their professional worlds.

While analyzing the interview transcripts, we decided to bring the two voices together to show the commonalities and differences more clearly and to facilitate a reading across the variety of viewpoints. We were fascinated by how

1 The interview with Nicholas Sungura was conducted by Kirsten Rüther in Hannover, Germany in July 2018; Marlene Wagner was interviewed by Martina Barker-Ciganikova and Kirsten Rüther in Vienna in August 2018. 
centrally the importance of the human element featured for both Nicholas and Marlene in an otherwise technically dominated discipline.

\section{The importance of the human element in the technical world: concrete does not cry!}

\section{Nicholas}

Until, let's say, ten years ago, in the civil engineering course at the university, risk management was just a topic at the end of the chapter, somewhere, summarized by formulas: if this risk eventuates, the cost of the construction project will increase by so much money and the delay in completing the construction will be so many years. Those were just formulas. We were missing something. That's what I felt. We were missing the real people who are supposed to manage these risks. Who are they? Who are these people? Do they know what a risk is? Are they able to identify it? Does our risk awareness have something to do with culture? Does it have something to do with the training we received at the university? So, I said, "let's first of all define what a construction project is." Until then the engineering course focused on the technical aspects of a construction project. But then, during my research, I submitted the argument that a construction project is first and foremost a social project because we are building, say a dam, for the people. We are laying a railway line for the people. We are not just executing a project for construction's sake, the construction is meant for the people. And so, we have to find out what these people we are constructing for need. We need to engage them. And it is exactly here that a barrier arises. First of all, it would require of us engineers to leave our formulas behind and to receive the views and emotions of the public regarding the construction project under consideration.

You know, a construction project is like an animal in its milieu, like a lion that has to go and hunt, that depends on the environment for its resources. Similarly, I look at the country in which we are realizing a given construction project as its milieu. The required money, maybe from infrastructure development partners or investors, comes in to feed this project. So, let us imagine a construction site as a living thing, made of technical aspects and social aspects so that we have something like a techno-social organism in the construction milieu. Let's start looking at the emotions of construction practitioners because concrete does not cry; but human beings do. And when I attend the site meetings of a construction project, I become increasingly aware of the emotions of those in attendance. On the first day everything is good, things are perfect. Six months later, people start noticing that some payments were delayed. Or when it rained it didn't increase my money - money that I would have claimed as compensation for bad weather, and that is already a clash of interests! And those 
were some of the real risk factors. We are the people who execute a construction project yet we are the same ones posing risks to the realization of the project. It's not even the formula. The formulas we learnt in the classroom did not capture the scenario that the engineer could also be a risk factor affecting the execution of a project. As I see it, we engineers need to carry out self-reflection, go into ourselves and say, formulas are all good but we also need to remember human beings have emotions, they have aspirations, and above all, a construction project is first and foremost a social project. It is something we're building for the people.

Choosing the path of introspection in our work will create room for an array of insightful questions: Who are the people involved in the project? What is their level of awareness regarding the project? What is their cultural setting? What are they hoping for their lives with regard to the project? We need to look at every construction project as a living being, a techno-social organism. Developing awareness of the project as a living entity, having a lifespan like any other organism, would lead us to care for its wellbeing. We would ask ourselves: What are the things that can make the project sick? Like, if people demonstrate against it, if it's too expensive and then people say, "we don't want to construct it anymore, it doesn't make any sense for us." In my opinion, the aspect of complexity of the construction project has not been adequately addressed by the engineering fraternity in the past. Thankfully, this is now changing for the better.

\section{Marlene}

For me, architecture is always social. A house, a university, a school, but also your private home, there are people living in it so each building has a social component. The question I wonder about is why the kindergarten that we build in South Africa is called social architecture and why a kindergarten in Austria is not. It is interesting for me to apply what I have learned in South Africa in the Austrian context. There is more need for a more inclusive design and build process. To really focus on the process, the whole set-up, the stakeholders, the decision-making process, rather than the product, the fancy finished product. How did we get there and what is the potential of this building for people in its life as well as its afterlife? I have always been doing architecture in a very non-formal way.

\section{Interdisciplinary entanglements: History? - Phew no!}

How is the interest in an interdisciplinary encounter born? What led these two young professionals to step out of their traditional disciplines and to search for more elsewhere? What benefits were they able to identify when "borrowing" from other fields, both theoretical and practical? Being an interdisciplinary 
research group ourselves, we wanted to know more about this. We were particularly curious about the possible importance and contribution of social sciences and history to architects' and engineers' work. Although both colleagues apply an interdisciplinary approach, with respect to history, their answers differed significantly. While Nicholas puts historical (institutional) context at the center of his research focus, Marlene made a clear statement to our question of whether history was a discipline you work with: "Phew no!"

\section{Nicholas}

While doing my doctoral research in Kenya, I wanted to find out more about the history of infrastructure development in Kenya and the events that shaped the construction culture that is practiced in Kenya. I wanted to establish when the Ministry of Infrastructure was founded. When did it actually start executing its mandate? How did it evolve over the years? Who were the personnel in charge of it? When was the first time a Kenyan engineer was appointed to become the ministry's top administrator? So, I went to the Kenyan National Archives to find out more about the country's colonial history with special emphasis on Africanization of its civil service after Independence in 1963.

That was an approach we had not expected when in the research project we had speculated about the ways in which engineers would design research paths. We had assumed Nicholas would go to the laboratory, or a library, and just look at engineering books. But Nicholas had something in mind for which he needed to do extra research rather than tread the beaten path.

Because the role of the human element was at the core of my research, I needed to know, for example, how were Kenyans involved in the dams that were being constructed, say, in the 1950s? There was a water problem: to supply water to the population. How was water being provided? Who was designing these dams? Who was constructing them? How were construction projects set up? Who was financing them? Were there financial agreements in place? At the archives, I read memos signed by British personnel outlining the construction projects in Kenya. These documents served as my main source of information. They indicated the financing, the planned completion dates, the roles of construction practitioners, and the intended beneficiaries of the projects. Besides the Kenyan National Archives, the History Department at the University of Hannover has a very good library with material I used for my research. Notwithstanding these sources, I did not find information on Kenyan engineers in professional practice during the time-frame that my research focused on. I would read an entire book and it would 
only vaguely touch on construction activities in Kenya in general, only scratch the surface, highlighting the acute shortage of housing for Kenyans in urban areas. And that would be as closest to construction in Kenya as the sources went. This is what characterized my research venture: collecting knowledge from wide sources, looking for clues everywhere, and trying to interconnect them.

The archival work was very important for me. In my view, history has an important role to play in the life of construction projects. Supposing I just arrive at a stalled project where I have been appointed as an engineer tasked with resuming the building work, well, people will see walls coming up... the stalled project restarting. However, I would surely build better if I delved into the history of the project. For instance, can I establish why the project stalled in the first place? The construction work commenced, say, ten years ago, and then six years ago it was abandoned. To understand the reason why it was abandoned is beneficial for the future of the project. Because we could restart it now and if we didn't learn from the past, we could abandon it again. Sometimes the financing changes. We have development partners who come in and say, "we have this set of conditions. This is what you must fulfill in order to secure funding for realizing this project." Then after some time they pull out of the project due to one reason or another. We would then need to get new financiers. The new financiers would want to know what happened: "Why did you stop the project at the time?" So, somebody with a project memory who knows: "Aha! We started on the wrong footing, we didn't estimate the quantities of building materials well, we underestimated the role of the community, we didn't know that fifty kilometers away a railway would be constructed and that would make this project irrelevant. We did not connect with planners to find out what, say, the five-year plan is." Once I enter into the historical context, of a project, I come to the realization that I need to leave my formulas behind. The formulas are still important, though I now need to actively engage with the people, with the social dimension of the project.

From my experience, the entangling of disciplines is rather new to my engineering discipline, I struggled to find supervisors who were willing to oversee my research work from an interdisciplinary perspective. It was an uphill task! I had to argue my case to prospective supervisors aiming to convince them that it is the people involved in construction who determine the life of a project, and that the mind-set and emotions of these people have a direct influence on the outcome of the project. ${ }^{2}$ For instance, when the operator of a machine on the construction site falls sick, and we are

2 Nicholas Sungura, "Der Faktor Mensch bei der Risikosteuerung öffentlicher Bauvorhaben in Kenia”, translated “The Human Element in the Risk Management of Public Infrastructure Projects in Kenya" (unpublished Dr. Eng. diss., University of Hannover, 2016). 
unable to find a suitable person to replace him or her such that the construction stalls, what do we then do? We would need to talk to one another, we need to enter into negotiations about what to do next. These negotiations are not there in the textbooks. In our search for workable solutions, given such a scenario, we need alternative approaches, perhaps, from other disciplines. I borrowed concepts from biology and mathematics in my research. Using the concept of cybernetics in biology, I imagined the construction project as an organism capable of balancing the tensions it experiences during project realization. The capacity of balancing its tensions aims at preserving its life. This capacity depends on the persons involved in the project. Using game theory in mathematics, I imagined the construction undertaking as a game. In the construction game, I considered the two main players to be the project owner and the community intended to benefit from the project. I assigned the role of referee to the engineer. Several fascinating scenarios between the players of the construction game emerged. The complex interactions between the players could not be modeled solely by use of engineering techniques. Thankfully, I found two supervisors who were willing to embrace this approach; their openness signaled a trend that is changing. A trend in favor of interdisciplinary approaches in engineering.

Marlene was also looking for new ways to turn "ordinary" architectural knowledge into meaningful design projects which are pushing forward not only ideas but society more generally.

\section{Marlene}

My focus on design-build architecture over the last years has been more of a coincidence. I attended a design-build course at the Vienna Technical University to realize a kindergarten in Orange Farm, South Africa in 2005. I did not have much knowledge on South Africa or construction at that time. But I was motivated to realize and implement a project, which ordinarily in architecture you start doing at a much later stage, at the age of 40. For me, working in this new environment showed me that architecture could also be (change word order) something else. It made me believe that architecture might have a power to do something more than just giving the space, perhaps even a positive impact on the global scale?

Doing design-build architecture is doing a different kind of architecture production. It is not equally accepted as it is not the formal established and over-regulated way of architecture. For me personally, the potential of design-build is about a collective approach and about trying to focus on the process rather than the product at the end. I hope its ok to place this further down. I believe it is more understandable to explain design-build and then my approach of Social Architecture. 
The biggest difference probably to formal architecture is that in design-build, the layperson and the designer also become the implementers. Design-build can be done with an educational approach at architecture faculties or also as an architectural practice - as we approached it with buildCollective. So, for example, Austrian, or let's say European, students design a classroom during the university course for clients that would not have the means for this service, and then, for the implementation and construction phase, they go on site, for example in South Africa insert comma here and work together with local client and construction team on the implementation. In ordinary architecture, the role of the architect is comparatively small. The creative design is some 10 percent of the work of the architect. The architect hands in the plans and then the construction company takes over and makes the rest. With design-build, you can have control over the entire process. You have influence on construction and you can design on the site. You work together with students, volunteers, suppliers, users and the broader community. So, you have to make a lot of decisions on the go, you need to have control and customize the process, you manage the construction site and sometimes even organize maintenance and actively influence the use of the space.

This kind of architecture - design-build between the global North and South, working in different environments and, as I like to frame it even further, "Social Architecture" - is trans-disciplinary. Social Architecture combines both theory and practice and spans a huge field of activities. It is a journey of development together with whoever is on the team, European and African universities, governmental institutions, local communities and users. The main idea behind this is to remove hierarchical boundaries and to create more of a family design and construction business. Let everybody have a say and balance the different needsand interests to create something meaningfull and to learn from each other. Ethnographic and sociological skills are needed. Qualitative research methods and skills on how to conduct interviews are required. As an architect, I am always pushed towards seeing something others don't, trying to convince user and client about the future reality. Architects are envisioning something that is not even there; that's the design process. If we design a house, I have to see it already there; I have to faciliate and guide people into an envisioned reality.

For a considerable time now, Marlene's particular role has been to translate and transfer design-build processes between continents and different professional and social settings.

Before and after a design-build project with students, I try to incorporate elements of self-reflection into the university architecture classes. I try to sensitize students and 
apply reflective methods: in what way did the experience change them? What impact did the project have on them? This is often not really supported by the architecture school, so it happens that the main professor leaves the class when I start talking about "these social things" in a technically dominated field. So, the set-up is difficult. Many of the qualitative research methods and approaches I apply in my work, I just made up for myself on the go, on the construction site, through books. It is just from my personal interest, nobody ever gave that to me. It is my personal drive to look into books, to have discussions. As a matter of fact, young Austrian architecture students do not know much about Mandela, apartheid or townships, so I need to give them some background. Another source of information for me is the local knowledge, the individual stories and histories of the people you work with. Everything we did was always in the process of making. All these facets combined make up my idea and notion of the space I work in. I am grateful I had a lot of freedom in these past years to develop myself and just to try out. Now that I am back in the Austrian context, the word seems to be "real-world laboratory or living-lab" and describes what we have actually been doing, practicing without even knowing this word.

\section{The role of architects and civil engineers with regard to housing}

As we ourselves have been committed to the study of housing in our research project, we naturally asked a number of questions with regard to that particular field. What is the biggest contribution and potential of architecture and civil engineering toward the study and planning of housing? At which stage of the construction process do the architects and engineers have the power to effect the most change? Where do they leave their imprint? Both Nicholas and Marlene are, of course, committed to infrastructural projects other than housing. Yet we were curious about the kind of input they would bring to the field of housing where a lot of cooperation and interchange happens between the respective disciplines they and we represent. Do professionals like Marlene and Nicholas have the potential to create more than a mere living space, to design more than just a physical structure and lay the basis for making a house a home?

\section{Nicholas}

The magnitude of a housing project in comparison, let's say, to a dam project may be smaller depending on the variables under consideration. But we talk about housing units, we talk about the state, pledging: we are going to provide 1.5 million houses, or housing units, in the next five years. Then areas have to be set aside to construct those houses. First, there is what we call the physical plan, that is to say, the area has to be zoned, this is done by physical planners in a given zone. Then maybe they say there'll be housing estates, maybe one estate having about three 
hundred houses, for example. And there is a standard house, like it's one house repeated three hundred times. The architect will design that one house and say, all right, that is what a model house will look like, and we are going to have them all around in this way. The engineer will then come and say, "all right, if the houses are to be spaced in this manner, then this is where the main roads and access roads need to be. We need water, so this is where the water points are going to be, to connect them to the dams." We also investigate the soil. We say, "ah, if this is the kind of soil, these are the kinds of foundations we need, and this is exactly the kind of reinforcement we need for the columns and house walls." The engineer is integral to housing, in fact he's the one who realizes the dream of the architect. The architect will give her idea, her housing design to the engineer, and the engineer will then execute it.

We wanted to know more about the actual living and dwelling conditions. Beside roads and sanitation, there are the real houses, the spaces occupied by people. Does an engineer have an impact on their quality of living? How can she or he help to improve the living conditions?

\section{Nicholas}

From an engineering point of view, I say, "okay, if this is the house design, what's important for me, if I were to be the one to occupy the house: is there enough daylight?" I need to figure out: where does the sun rise in the morning and where does it set? Because that tells me where the windows need to be. There is no need for people to live in a house that is dark most of the time. How far apart should the housing blocks be? Because I need to consider the shadow cast by adjacent houses. During the day, if there is a shadow that follows the house, I need to space the houses apart. I would also need to consider how far away the water point is, because sometimes there is the situation of people having to go and maybe fetch water, in case there is a problem with the piping of the water. How far would they have to walk to access the water point? I also try to imagine the needs of the people who choose to live at the location in future and would be having cars. Where could I locate a car park? Is there a market nearby? Are there schools nearby? There is no need of constructing housing units deep inside the bush if there is no school in the vicinty. I would need to consider families and their needs. How does a model family look like? Is it a family of two or three children? All these aspects come together and provide vital information to enable me carry out the engineering design of the housing units.

And what if, notwithstanding all the meticulous planning and calculations, the implementation phase takes its own path? The Western model of nuclear family is challenged in African societies and living arrangements might encompass a range 
of blood and non-blood relatives one conceives of as family. Do engineers have a solution for assembled family set-ups? How does one actually plan knowing that the houses will be used in different ways from the original design anyway?

\section{Nicholas}

We have a term for it. We call it the design capacity of a house. So that means, when I design the house, I can say this house is for five persons. That is its design capacity. But it does not mean that only five people will live there. Because we have experience of houses with double the number of occupants. But for purposes of design, we need to quantify the building materials and say it's going to require so much cement and sand. We need a design basis to be able to calculate for sanitation of the solid waste or liquid waste; we need to know how many people are living at a given location for us to determine the sizing of, say, the potable water or wastewater treatment tanks. So that is the one point. But once these houses have been rented out, there is no chance whatsoever of making sure that only five people are living in a given house. In order to cater for a possible overload of the system we have designed, what we can do as engineers, when we have a design capacity of, say, five persons, we use a numerical factor. In the formula we say, "let us factor the load in our design by 25 percent more, so that in case instead of five there are seven or eight persons, they can still safely live there." We do it using the multiplication factor in the formula. But in real terms it doesn't mean that only eight people will live there; they could be ten or more; and when such scenarios happen, the designed system begins to fail because its capacity has been exceeded. Then we realize the piped water is not enough the population at a given location, or it takes a longer time than planned for the sewage from the housing units to be safely disposed.

Marlene was very passionate about the role architects may play to ensure housing projects amount to more than just technological and pricey designs.

\section{Marlene}

The potential of architecture is to create alternatives, maybe different typologies, different materials, and different processes that can turn it into more: that can make it a home; that can make it an income. That is definitely architecture's role. The problem is there is no architect involved most of the time. There is the construction company a general contractor, especially if it's a governmental project. The plan is already there, and any construction company can make an offer: "We build so many houses for this price, even offer mass prices." The bigger the company, the better, so there is no interest that there is an architect involved. The architect can make a spatial benefit; create a better space, maybe also a space more flexible and adaptable for people. 
The architect, most of the time, had better or more ideas than what you see in the outcome - what is left of the design after fighting for budget, fighting with the client for what is actually needed, fighting with the construction company, fighting or rather hacking the regulations and norms of the government and engineers. I think being an architect is really this umbrella position, that is natural to architecture, between theory and practice, between drawing board and construction company. At least that is what I also hope to see and, to work in this complex interdisciplinary field, it's kind of what we have to do in architecture.

Architecture is the social glue in the making of space between disciplines, or the creative glue. It pushes the limits. The engineers, for example, often stick much more to the rules and the books, also because of the responsibility they have. But it is definitely the architect who has a totally creative job to balance all the needs. The material can do that, the user needs that, the construction company wants that, the client wants that, now make one thing out of all of that. That is also why in my opinion interdisciplinary work is totally natural to architecture. I believe that architecture can envision things.

On the construction site the reality-check happens and, one needs to move forward; every day on site costs money. It is not possible to sit on site and discuss for too long neither design issues nor social issues because the project cannot afford the digger one more day. So, you just have to take decision after decision, in the design and especially in the construction process. To always think ahead, to visualize something ready that other stakeholders cannot imagine yet. On the other hand, there is also the problem of architects: that we tend to fall in love with our own ideas and do not listen enough to others. Then it is not a participatory process anymore and you will lose partners in the kind of architecture we do. Architects need to envision but not impose their own vision over all the others. They need to listen.

\section{Involving the community, involving the professionals}

Both Marlene and Nicholas emphasize engagement with the local community as the alpha and omega of their work. They both believe the success of a project depends on the degree of involvement of the local community. Is the local community consulted? Do people have a say? Are their wishes heard or, even more importantly, respected? If so, there is a high chance of accomplishment. If decisions are imposed, there is a higher likelihood that something will go wrong along the way and the project will stall or fail. But who is the local community? Who is allowed to represent it and have a say? And who engages with whom in the end? The community with the professionals, or vice versa? Unsurprisingly, the interviewees did not manage to answer all our questions. 


\section{Nicholas}

When the engineer decides to engage more with the people, he then has to leave the office where he is drawing and designing and do more work with the community, and sit with the people, maybe organize forums. We need to have, say, a community day, we are collecting ideas, say, at the community market place. We intend to, let's say, rehabilitate this village road, or put a new surface on an existing all-weather road: "What do you think? Do you want it? Do you need it? Or would you like this road to be wider, or would you like it to also go into two more villages?" So, this work that I have come to realize is necessary, to engage with the community, unfortunately was not incorporated in the university training. Because when I go to my civil engineering course, I go to mathematics, I go to physics, I memorize and apply countless formulas and I come out of college in the end and I have my degree. But there is not much emphasis on people, community. Already, the way the course is tailored, it is so technically inclined, something which I can partially understand. But it neglects the social aspects: for whom are we actually going to work? And maybe it is now more often the case that the projects are becoming more complex to execute. It is a wake-up call that the new engineers who are being trained should be receiving maybe 10 percent more social skills than has been the case before. Because when I go to the village, the people I interact with don't care about my formulas. They don't even need to know that my formulas exist. Maybe they know I will draw something. Then they call it, as is the case in my village, a map. They say, "oh, he will come with a map, and this map is what he's using to build the road." That's all. But of course, it's not called a map, it is a design plan, and it has technical validity, but they don't need that. They just know I will come with a map. But they need me to know that the planned road is important or not important for them. They need me to provide them with information addressing their concerns: when this road is being constructed, will they get jobs, will they be allowed to work on that road, or will I bring my own workers? Because depending on what the contract model is, they may even choose to protest and say, "okay, if our children are not going to get jobs here, don't construct the road. We want a road that will generate jobs in the village." So, these are many things that we have to learn these days. And even for the engineers who have been, say, long enough in the profession, it may seem as if the train has already passed them by yet I believe we all have room to learn because the community is very, very important.

Under Marlene's tutelage, the self-built suspension pedestrian bridge over the Mzamba River in Eastern Cape, South Africa was built between 2014 and 2016. It involved the local community, the NGO buildCollective, the architecture faculty at Carinthia University of Applied Sciences and many other contributing individuals, including students, volunteers, consultants, and supporters. The 
project won several awards; a documentary and a book were released after its realization. ${ }^{3}$

\section{Marlene}

As for the bridge, that was not our idea. The community approached us, that there are people dying because of the river. Sometimes it floods, and the connection to get food, education, and healthcare does not exist. There we had to undergo even environmental impact assessment because it's on public land and in an environmental protection area. Of course, each project differs. It is much more important to have a participatory approach and community involvement in the public infrastructure because there is nobody to hand it over to. It is always a big challenge how to balance things because sometimes the user is not even interested. Just give me a building, they seem to say. I do not want to be included in the whole design, they say. But you need the community to be involved, so that they can take care of it. Government trusted us to take care of it. We got the South African Sustainable Architecture Prize and I was asked: "There is a similar bridge in the neighboring province that got destroyed by the community. How can you make sure it is not happening to your bridge?" "Well, it is not our bridge, the request came from the community and there was a steering committee and the whole decision-making process, from the set-up how high the bridge needed to be, from the whole talking with government, getting the environmental impact assessment and so on." The community steering committee was made up of political representatives, traditional leader, and just community members from both sides of the river, women and men; it was really nice. In my experience, working in the countryside is very different compared to the city, the unity and self-organization, the whole traditional system is still in place; that is why it was much easier to work with this alternative set-up. On the construction team, there were never more than five to eight Europeans as compared to ten or twenty South Africans on the site. The team on the construction site did not have any special technical knowledge; some used to work with us before at the construction of the schools. And then also it is a very rural community, so everybody is kind of handy. The bridge design was simplified, every single part of the bridge had to be light enough to be carried because there was no road. So that again influences the design, and then you just screw. And screw. The material was steel, it is $140 \mathrm{~m}$ long bridge, and the pylon is $15 \mathrm{~m}$ high. We spent three years on this project. I believe

3 http://buildcollective.net/onsite/bridgingmzamba/. Besides the bridge - the NGO's most famous project - the co-founders Marlene Wagner and Elias Rubin also realized other projects including education facilities, classrooms, schools, workshops, and water points. 
that architecture, because it spans a big field between design and construction, really has the power to be an enabler, for people to learn more about construction, and to have a say. It is just that in participatory design-build architecture, projects need to be designed in a way that laypeople can be involved in the different phases. They are a kind of educational project for everybody involved. This requires more management at the beginning, but generally I believe that, especially considering the South African housing shortage, it should be made possible with funds available from the government so that people can build their own homes as skills are there.

\section{What are real houses?}

Where there is housing, people often need space to produce goods, to offer services and to subsidize family incomes. This aspect is often neglected both in theory and practice when housing is conceived of as a mere physical structure. The state and construction companies promote a low-cost philosophy, be it in social housing, home-ownership or site-and-services schemes. The target is to save costs wherever possible. Those who offer the lowest price win the tender. This philosophy is in stark contrast with issues of maintenance, longevity, high sensitivity, and the complexity of housing projects more generally. Cheap material, repair, and overcrowding quickly become a problem. As a result, intentions to regulate people's lives often clash with people's understandings of housing as a place of work and belonging, community cohesion and identity or as a space that provides social benefits be it valuable support networks, neighbors, friends or sharing childcare duties: "The sign of a material house is an illusion when no system of institutionalized expectations is in place to connect the physical structure (house) and the range of functions it is assumed to provide to the resident: safety, security and health benefit." It looks like it is a house, but it is not one. It is a "non-house".

\section{Nicholas}

First of all, I would challenge the planners who tell us about low-cost housing. They should tell us which costs they are talking about. Are they talking about construction costs? Are they talking about maintenance costs? They have to tell us which cost is being referred to. Or are they talking about the rent that the tenant will pay? For example, maybe I'm saying it is low-cost, and this means when the person is going to rent it, he will pay eighty Euros for one room. But if I just say it is low-cost because it cost me a hundred million Euros to construct, I will also have to say what the lifespan

4 Tess Lea and Paul Pholeros, "This is Not a Pipe: The Treacheries of Indigenous Housing," Public Culture 22 (2010): 191. See also for a more detailed discussion on the non-house syndrome. 
of those houses is, before, say, a renovation is done. Is it five years before we come back and paint again? Is it ten years before we change the piping again? So, is it lowcost now because we are using cheap building materials that can get damaged after three years, or even after six months, and then we have to replace it? This is what is seldom talked about in the open. It could be a strategy to sell the project, to attract financing, it could also be a strategy to attract the support of the public. Because when the public hears, "oh, housing at low cost," many people are led to think that they can afford to rent or purchase such houses. But they are not told about the maintenance of those houses. Does it mean that if the state builds the house, it is now the cost of the tenant to maintain it? That is often not explicitly communicated. Even if it were clarified that, "okay, we're building the house but it is your cost to maintain it," then people may realize that actually it's not low-cost at the end of the day. The question remains: can the calculations of the housing developers tell us how much it is going to cost to maintain that house ten years from now? To change a broken sink, to change the wiring if there is a wiring problem, those are the silent aspects that become clearer the moment there is damage to be fixed.

\section{Marlene}

The problem in South Africa is not the building itself. The buildings, especially in this climate, do not need air conditioning or high-tech materials to create a good room climate. You can design the house quite cheaply, low-maintenance, self-sufficient, especially within the standards of the RDP housing program [Reconstruction and Development Program]. I believe that a big problem is for the government to allow alternative design strategies and construction material to be tried out, but I don't know what happened in the last two years. Of course, you have good architects in South Africa and they all put proposals for alternative housing models. There are some interesting ideas with different typologies so the owner can, for example, easily rent out a part of the house to generate income. As non-South-Africans do not qualify for the RDP housing program - the post-Apartheid promise of free houses for all South Africans - there is the problem of the so-called "backyard shack," meaning that people informally rent out an inadequate self-built space in their backyard. In order to tackle this problem, South African architects started designing houses with two entrances and which can be easily extended. The South African beneficiary of the RDP house can formally rent out a room which generates income while the non-South African resident is not living in a backyard shack but in a real house with an address.

The other side of it is that this rental system is not controlled. So, for example, the south African RDP house owner can make the Zimbabwean tenant suffer by obliging him or her to pay I don't know how much rent for a small space. That is another issue. The space and construction are not a problem. It's the political will 
and the money flow. I am talking about ordinary housing now, not even ecological construction. Just better planned typologies of housing to meet existing needs and processes that take into consideration the reality of the users.

In South Africa, social housing is basically for rent. An RDP house you would not call social housing. That was something new for me to see, there is a whole different understanding and system of housing programs as compared, for example, to Austria or to Kenya, where it is more common to rent, not to own their house, they are fine with a flat. In South Africa, this promise of a "free house" of the post-Apartheid government is so strong that people want a "free house" as promised. The end-users already have a certain idea, expectations of how their house should look like. Now you as an architect come, trying to convince the government and the end-user that a different design might be better, but it is really not supported to try out case studies of different typologies or different set-ups. People do not want just any kind of house. It is the promise they got with democracy and the RDP program and that is how the house should be. It is also a marketing strategy for the government to advertise itself. We give you a house. This year we deliver so and so many houses. That sounds better than to say that we will build a block of flats. But the problem is, after a while, especially in the outskirt areas, the problem is not only with the house or the architecture of the house, but mainly with the zoning. Because what is allowed to be on the land, it is just residential zoning, which kills the whole income generation possibilities of people. To do business on the land is not allowed and also the government keeps the land. You never get the land; you just get the top structure, the house construction. You are not allowed to sell the house, so it is not a real asset, and you are not allowed to have your shop, which was your income in your former place. Now, when you are transferred from an informal settlement into a new housing development in the periphery, you have your house but not in the same place, and you are without your social network. This house, if it's nowhere, you have your flushing toilet, but you cannot pay your electricity anymore. It's not a shack, it's not corrugated iron, it's a brick house, but that's also it. You have a safe structure, nothing more. The construction company consumes so much money; it could besides being a real home within a social network, the building process could also support economic and educational features. But for that you need proper management and policies and capable construction companies to implement it. It is very difficult to try to convince the government or a construction company to do something differently, no matter if in Austria or South Africa. If you want something different, there is always a big discussion. Construction companies just try to get as much money as possible. Funding is coming from the government, and the cheaper they can build the houses, the more money is left for the company. This is not a system that supports a different, alternative way of doing things. 


\section{Reflections on institutions, complexity, and communication}

The network of actors involved in a housing or construction project involves many more participants than engineers, architects, and the local community. It is like a web linking different corners and (hi)stories. Besides the people who receive the construction - the end beneficiaries - there are economic players, including banks or international donors, physical planners, construction companies, and research institutions. They are engulfed by the omnipresent state. An increased number of actors often means more complexity and an increased need for communication to avoid misunderstandings. This again puts pressure on the budget and timeline of each construction site. In our research project, we conceive of housing as not only a "physical frame" ${ }^{5}$ of everyday urban life, but as a social, cultural, and legal network of relationships between various players, each of whom cultivate their respective interests. These diverging interests need to be accommodated. Are there particular ways of engaging with the institutions in order to push through a certain dimension of the project, or to create awareness? While for Nicholas, who has work experience in public service in Kenya, the state is the most important actor to engage with, Marlene, a co-founder of an NGO, also cooperates closely with (European) private companies while searching for funding.

\section{Nicholas}

Yes. We are very aware in my country that the state is alpha and omega. Because the state provides the framework allowing us to practice our profession. The state licenses the engineers who can practice the profession. The state is the one that approves the construction project to be realized. That is why I can't just wake up and say, "now I like this place, I want to build a bridge." I am required to seek approval from the state to implement the planned project, and the state has the last word. The state provides the framework within which infrastructure can be executed.

We say the state has no face; it is faceless. But we feel its institutions. For example, if there is a conflict on the construction site, the aggrieved parties go to court. So, the court is an arm of the state. I have two options to practice as an engineer in Kenya: I could work in the Ministry of Infrastructure, inside the government system, so to say, or I could work in the free-market economy, as a private engineer having his own engineering office. If I'm in the Ministry, I apply my skills to execute the state's plan. And the state has, say, a five-year plan, a medium-term plan, maybe it says in the next five years our focus is on schools. So, the efforts of

5 Alison Hay and Richard Harris, “'Shauri Ya Sera Kali’: The Colonial Regime of Urban Housing in Kenya,” Urban History 34 (2007): 504. 
its technical personnel are geared towards realizing that objective. And as an engineer I can't change that plan. I cannot because this is how the state is even marketing itself. And an engineer in the Ministry executes the state's infrastructural agenda. He goes to supervise the work on the construction site to make sure that that school is being constructed according to the budget that was set aside. Whether that budget is enough is another question altogether. It is also worth noting that, there is a government of the day and each government has its own development agenda. For instance, one government can say, "our plan is infrastructure, we want railways, we want roads." As a result, that is where the its resources will be channeled to. It comes as a policy.

Nicholas has some particular comments on the complexity of construction settings:

The complexity of a construction project enhances the need for increased use of interdisciplinary approaches. The required initiative needs to come from the engineers themselves because, yes, we have the drawing pen and we have the drawing board. And we have the technical knowledge, but that is not enough; we need to work with other non-technical disciplines. I acknowledge that if we work with other disciplines, it does make the construction project more complex, that's for sure. I mean, it's easier when somebody says, I'm just doing it alone, for then I can make decisions quicker. The more the number of interested parties sit on the table, the more players there are to satisfy, and such a setting calls for more compromises to be made. In our time, we need technicians who are also willing to say, "okay, I admit it is more complex and time-consuming to design a project in this manner, as I now consider your interests. I am now able to expand my thinking and increase my awareness of the significance of the project with your concerns in mind." And then the project financiers also need to be able to agree, "yes, we are willing to continue being part of the project, although it will cost us two hundred million shillings more. We think we are better off implementing the inclusive design solution that costs more than spend two hundred million less, only for the project to not be used as projected. Because we are also looking at the rate of return of our investment." The cost of an infrastructure project is justified by the accrued benefits from its intended use. The more people are likely to use the railway, to use the dam, to use the schools, the more sense it makes to implement the project, and which eventually yields the benefits for which it was constructed. And I think, if we as technicians can open our minds and appreciate other professions and accept that an infrastructure project is not only a technical project, but also a social project, then I think that would be a good start. This approach will not eliminate risks from the construction site, because life is full of risks, anyway. I see the interdisciplinary approach as more conducive for risk management. We don't talk about 
eliminating risks in infrastructure projects, we talk about managing them, because some risks will eventuate anyway. Could we join our efforts so as to mitigate the impact of eventuating risks?

\section{Marlene}

Most of the funds and money for our projects are coming from private people in Austria. We do projects with local grass roots organizations, with clients that don't have money so it needs a different set-up, and we collect money on our own. We also received money from companies or development funds of the Austrian municipalities, but the biggest contributions are from private people. These were the biggest amounts, they trusted us, they know our work; they often have some kind of relationship with South Africa. As an architect working between cultures and income classes, I can be the translator between needs, between users and clients, because I am on site.

For me, these design-build projects with universities also have their limits. To design and build a house with 20 students and 20 community members in just seven weeks is quite... there are a lot of risks, you push all participants already quite to the limit, if you just want to do the design and build the house. If you also want to take into consideration cultural issues, learn about history, then you will never end up building in the framework of one term given by the university structure. That is why I also tried to convince partner universities to do the course for at least a full year, not just one term, because then it's much easier to have a longer design and transdisciplinary learning process. But with the regulations of the university in Europe, it did not work. Then I tried to set up collaboration between Wits University and the FH Kärnten [Carinthia University of Applied Sciences], but the terms are completely the other way around so it really did not work out, both sides being very opposed. The Austrians saying, "we cannot change anything, the Africans have to do so", and South Africans saying, "no, why again should we change our schedule for Europeans?" I took some of my South African students on site, but not as part of the regular course, rather in a way as a volunteer workshop to team up with the local construction team, which went really great. For me it was frustrating that despite the many years of working with the European universities, we are still in the same set-up as when I was a student. This design-build practice in the Global South did not develop in the way I believe it would be necessary.

\section{Of straw and clay and stamps}

Discussions on the use of building material have always played a pivotal role in the housing and construction industry. Our archival research in The National Archives in Kew, UK revealed that few other topics were examined so prominently and in such detail among British colonial officers as building material. 
The debates were highly technical: which material to use for whom and, most decisively, how much would it cost the taxpayers? Corrugated iron or mud and wattle? Stone or cement? Imported or local? All had their pros and cons and only seldom was there a univocal reply to any of these questions. The search for answers has not ceased with the demise of the colonial period. Against the backdrop of the scarcity of resources today, the discussion on more sustainable and ecological solutions gains even more prominence. One of the most important questions to answer remains: what type of building material do dwellers desire?

\section{Marlene}

In our work, we did experiments with alternative materials. We did projects with, for example, straw-clay for better insulation. Especially in the Johannesburg climate this material supports a good room climate. But you need a load-bearing structure, for example, out of concrete pillars and steel trusses. We try to produce as much as possible on site, the trusses and pillars included. As a way of building up the local construction team: that you go through the same process over and over again, so that it can be pre-produced at some stage even without us; and that it creates income-generation for the local team while there is no big project going on, but they can pre-produce pillars and trusses that are then later bought by the universities. There is a lot of learning, and long-time guidance and collaboration there. We developed the system for classrooms, with self-built pillars and self-built trusses and the light-clay infill. We went to the Housing Department in Ekurhuleni Province because there is an existing housing program which allows South African citizens to apply not only for a house from the South African government but also for money to build their own house, provided that they match the application criteria. But I have never really seen it actually work. We had a lot of meetings, and we showed how it's designed and how it's cheaper, and more comfortable than the ordinary RDP house design, but it never worked out.

But I think the problem was that we were not South Africans. It is very tough to get into the business: Like everywhere, the construction industry is corrupt, so as an Austrian, how to get a contract with the government; as young architects, how to get into the system; with the township crew, how to get in the system; with alternative material. . all at once, to get into this funded housing schemes is very difficult. We would have liked to build some show houses. In our projects on private land, we could experiment a lot, but it's different on land for a publicly funded housing scheme. So, we had a lot of meetings with the government, trying to convince them that they trust us to make a show house, to show them that the material is fine, that the community can do it on their own, but it never really worked out. 
For me the main motivation for using straw and clay is because one can build ecologically. First and foremost: to reduce concrete. The idea was also to try something new, something that is easy to work with. To have better indoor quality. Straw-clay is a natural insulation; it has better insulation quality than a concrete brick. Also, this alternative wall infill is something that is workable for everybody. You do not need special skills. For the main load-bearing structure, of course, you need a professional team, but as regards the straw-clay infill, anybody can do it. I can show you in half an hour more or less, and then after one day of guidance you can do it yourselves.

But then people, they do not want straw and clay houses, they want concrete, steel, and glass architecture. At first, there was a lot of skepticism because it's earth, community team members would see earth houses as outdated. Plus, the government has the program to "eradicate all mud schools," it is really "anti-earth" and antinatural building materials. It all depends on the milieu; the rich people want green, ecologically built houses. It is the same in Austria, working-class people don't want or care about a clay house; it is something you want if you have extra money and you can afford an environmental consciousness or the time to care about ecological issues. But because community members in South Africa have been working with us for such a long time and experienced that it's really a better room climate inside a straw-clay insulated house, it keeps the inside warm while it's cool outside. We could show participants, for example, how much money you need for a square meter of concrete bricks and how much for straw and clay. The straw and clay infill depending on availability and context in mass production would of course be cheaper.

To officially build with alternative material, you need a formal approval that this material certifies as construction material. This costs a lot of money. You have to go through a special process, not if it is your private house, but for public construction. We tried to do some testing via cooperation with the South African Bureau of Standards and also with engineers of the University of the Witwatersrand and the Carinthia University of Applied Sciences but then another project came in and we just could not afford it.

The bridge project is a completely different project because it's public infrastructure and one needs to comply with a lot of different regulations. You need engineers to calculate forces. With a house, you have a span width and forces you can calculate as an architect. For the 140-meter-long suspension bridge, we had to work with engineers. A Swiss engineering company donated their time to calculate - which is not an architect's job, but an engineer's - to get the stamp for the structural issues. The Swiss engineers calculated everything, but to get all the approval and submit the application with government for the structure of the bridge, we had local 
engineers. The main issue is the responsibility: the engineer with his stamp that proves that this structure is sound. That is in a way also a kind of donation, because we built it, so they need to trust us, it is not how architecture and construction work ordinarily.

\section{Dignity, language usage and living in lack}

Besides agency and governance, language usage is one of the three analytical layers through which we look at housing in our research project. The use of terminology in the field of housing and the way language in its broadest sense is used to (de)stabilize or establish power relations between the players is of great interest to us. Why and when are certain expressions being used? What is a "slum" and where does it originate? At certain periods specific words become en mode. When they are no longer required, attempts are made to erase them from public discourse. The Eurocentric framework for analysis has also been one of the reasons why, in colonial as well as postcolonial settings, it is deemed necessary to focus on the slum, the most prevalent "other" as opposed to European forms and norms of housing. Do engineers and architects reflect on language usage? Does it make any difference to them which term is being used? And do they come up with alternatives to express their dissatisfaction with the vocabulary at hand? We animatedly talked through these issues together.

\section{Nicholas}

I can't make much of the term slum. I use the word shelter in my work. I see shelter as an umbrella terminology that allows many possibilities under it. I use housing to mean a planned, structured kind of dwelling, you know, where there is a plan, like, this is where there are shops, and these are houses for families with three children, these are houses for families with seven children, that is now housing to me. But when I use shelter, I use it to also accommodate people who simply have something over their heads. It could be cardboards, paper carton boxes, they're just using it to protect themselves from the elements, and they keep staying there. Such shelter forms are thus less secure, they can be demolished more easily; houses are more permanent. I realize that if I just choose the word housing, then there would be many people who are not accounted for. Yet they are having shelter, they're having something over their heads protecting them from the elements. Many of them don't even have an address. It's not a registered address because they can move with their shelter. For instance, they could be staying at a given location today and tomorrow when there are demolitions, they can take their structures somewhere else and stay at another location. But still at the end of the day when they come home from their daily endeavors, that's where 
they come back to: to their form of shelter. And at the end of the day, we always need to remember; it is a human being coming back home, irrespective of the form of shelter.

From an engineering perspective, we also look at sanitation, where do the people in such shelter forms shower? Where does their liquid waste go to? Because we have to account for it, we have to drain it. There are very many aspects that need to be taken into account. Let's take an example: accessibility, how do they get to their shelter, how do they access their shelter? So, we need to plan for it and we would have to, first of all, acknowledge they are living where they are. And then to say, okay, if you are staying around this area, let's now think of communal toilets or communal bathrooms. If you need to shower, these are the common areas for showering. On such a basis, it becomes easier to plan for the necessary sanitation, because we are also responsible for public health. We need to design sanitation in order to prevent the outbreak of diseases such as cholera. I prefer to use the term shelter experience to slum. I cannot make much of the term slum.

Shelter experience, for me, may mean that dwellers lack a personalized bathroom, for instance. Their personalized experiences are: they lack. So, they are more inclined to use communal facilities, if these are available. For them, for the dwellers in that shelter experience, community means a lot. So that means we need to appreciate and acknowledge these shelter dwellers. We need to plan for them, which now brings me to housing, because housing, as I now use it, implies there is a plan. The engineer comes in and says, all right, I know you are staying here. We are all accountable for safeguarding public health. The solid waste management trucks cannot pick your solid waste directly from your form of shelter for lack of access roads. So, let us have a common area for solid waste disposal. Then it becomes easier to pick waste from there. As you can see, engineering is part and parcel of this. Wherever there are human beings, solid waste is being generated. I see the engineer as having a clear role to play in this shelter setting, and he cannot just distance himself and say, I'm only constructing housing schemes. We are inside this shelter theme, part and parcel. I'm not going to the person living in that shelter experience to get money from him and say, we want to build you something, it is the state that is responsible for building the required sanitary facilities and providing the needed sanitary services.

\section{Marlene}

When it comes to vocabulary, you need to use some words. I have not found the right answer in architecture on how to talk, what words to use: slum, shelter, shack. So, I was quite surprised, when I looked up academic work of development 
studies hoping to find an answer. But no, there is also no certainty about the wording, so maybe we as practitioners do not have to worry too much. But I think it's very interesting, also for me, more between North and South, not so much between disciplines. For example, in the collaboration with European architecture universities. The students wanted to call the project "We build a school for Africa." Most were fine with that slogan but I was not because we built one classroom for one village in South Africa and, of course, one cannot claim to build a school for Africa, the whole continent.

In the South African university context, when I went to doctoral seminars at Witwatersrand University people were also discussing, "how can we call a township?" because this is also not the best term. Okay, I thought, so the local academic experts also don't know. Next day, I was on the construction site, and it was really nice to take the university discussion onto the construction site, over lunchtime, discussing how to call a township. The community construction team did not like the term township; they liked location much more, which from my perspective would be much worse. So, the terminology I use is something I try to do very hands-on again. I feel that in discourse in architecture "slum" is okay to use. For me, in my thesis, I created for myself the category "non-formal" because informal is normal and is everywhere, it's just not formally accepted but it's not something extra, it's interwoven into everything. I don't like the word informal. I was actually getting on everybody's nerves for being the 'word police' on the construction site. But in practice, on a construction site, you can hardly discuss these things. So, either you make something up, or everybody lives with it, or you use something that everybody understands. But that is also the nice thing on the construction-site again. To do something interdisciplinary, cross-culturally with your hands, you learn a different way of communication. Then the word is really not important anymore, it is a code of profession, not of culture anymore.

\section{Frustrations and breaking points}

Notwithstanding meticulous planning, best intentions, careful and lengthy preparations, involvement of communities, and protracted discussions with stakeholders, something always goes wrong on the construction site, in the implementation phase of the project. The discrepancies between theory and practice, between provision and planning on the one side and implementation and building on the other, have been frequently discussed in academic literature on housing. When, where, how, and why do disruptions and wrongs happen according to the practitioners? Are these more likely to happen during one particular stage of the process than the other? And can someone be held accountable? 


\section{Nicholas}

I can hardly imagine that there could be one single answer to this, but there are many contributing factors. For me, first of all, it is the conception of a project. Who decides that this project is important? Is it the technicians? Is it engineers sitting in the office and saying, "oh, it is important that we build a dam?" Or is it a voice from the people, from the grassroots, that people say, "we need a bridge, we need to cross from this river bank to the other?" Because where the project initiative is coming from is actually a decisive factor in making the project a success. That is one point. The second point is the political will. You know, projects will not just happen unless politicians say yes. Because elected politicians are the ones who actually approve the funds to be disbursed to realize infrastructure projects. So, the politicians also need to have an awareness of the importance of the infrastructure being constructed. They need to be integrated in these projects. And the politicians have their own interests, too. For example, if he notices that a planned road will not pass where his voters are living, he may not support its construction. Thirdly, there is the aspect of us technicians ourselves: not accepting that a technician's or an engineer's knowledge is not enough to realize a project in its entirety. I may need to work with sociologists, professionals who have knowledge of demographics, who can inform us, say, about demographic trends for the next five, ten years. They could be telling us: we think people are going to live more in one area than another. In my limitation, I may just sit down at my drawing board as an engineer and say, "from the engineering point of view, this or that is the best route," but maybe the people with knowledge on demographics can tell me, "actually in the next fifteen years that area is less likely to be preferred for habitation, most people are going to move to a different area. So, find a solution to design the planned road with that information in mind." This is my message to, engineers: let's open up, let's work more with other disciplines.

Another aspect is that in the construction undertaking most actors tend to maximize their gain. For instance, if somebody knows that his property has a certain measurement he is inclined to use all that space, to build as many housing units as possible. For the sake of maximizing his profit. And in that regard other aspects that are important to tenants, such as "where do we hang our clothes to dry" may not receive adequate consideration by the property developers. Or, say, what about lighting during the day? There are actually some places, some rooms, that are always dark. People using those rooms must always switch on artificial light during the day to be able to access such rooms. Perhaps this is the face of greed: the drive to maximize personal profit at the expense of creating a humane shelter experience. I have regrettably observed that, sometimes, when property 
developers realize they could make an extra Euro at the expense of guaranteeing, for example, ample daylight for the houses under construction, they are willing to choose the option that ensures their personal gain. The option seems attractive to them as long as they are not the ones to occupy the houses....

\section{Marlene}

Where do things go wrong? In communication! That happens at every step. I would definitely say in communication and in the transfer of information, even within the same discipline. It is really not just the theory and practice, but it happens at every step. It's the change of media, every time you change media, which is the communication, if from the first idea... followed by sketch, then you start to draw something, then you draw an actual plan, which changes again everything, then you build a model, so every time you change the media, you translate the meaning and the idea. Then you have to prepare a detailed plan and it changes again and to translate this drawing into a real thing, it changes again... Even if it is just one person who builds his entire house by himself, the construction - the implementation of an idea into reality - keeps changing in translation.

\section{Nicholas}

Unfortunately, I have observed several cases of dishonesty in construction. The level of trust between the main decision-makers is at times very low, and fairness in the face of unexpected outcomes is not really practiced. How I wish I could hear something like, "okay, that risk happened, it cost you a lot of money, let me compensate you." The reaction I encounter more often could be verbalized, "let me save myself," so self-interest becomes the order of the day, and when everybody has self-interests to protect, then we always have a conflict potential. And the risk we all feared most, that the cost of the project will exceed our budget, ultimately eventuates, because we now have to engage lawyers. And lawyers cost a fee. We end up going to court, where the judge says, "first of all you must stop the construction work." The construction site becomes an exhibit for the judicial proceedings. While the construction has been halted, the money lent by credit institutions to finance the project is still accruing interest. So, we are not building at the moment, because we are stuck in court, fighting each other. And when we go to the construction records, we find that we have court cases that have taken ten, fifteen years, even twenty to be settled. And it's often taxpayers' money that foots the bill arising from such legal proceedings.

\section{Marlene}

Housing construction in South Africa (as in postwar Austria) is an economic machine; it supports the economy by implementing people's dream and life goal of 
owning a house. I did my thesis on Cosmo City, a satellite city of Johannesburg. ${ }^{6}$ In construction, the more mass production, the cheaper it gets. It's money; the construction business is a corrupt system everywhere. . the problem is always the money, and we now even see it in Vienna. I left Vienna where there was nothing going on; now we have a large need for housing people again, we would actually need to build 20,000 flats every six months to house all the people in Vienna. So, there is now a completely new dynamic in the housing market or housing construction in Vienna. You could also say what a great chance to change things, but, again, it has to happen so fast and as cheap as possible that, of course, the quality gets corrupted. It is easier to go for the known system instead of alternatives of material, construction process or ownership. It is very clear for the government where the money goes, it is very clear for the construction company as well.

When working together with Austrian and South African universities on the design-build projects I really try to include self-reflection into my courses after a field trip. With students we did little exercises, to find out where decisions were made, to reflect on the whole exercise after the process had been finished. They had to summarize their experience with the design-build course, what they had done for more than a term, now that they were back from the South African construction site. And I wanted to know whether they could describe it in one word. So, one of the students said, "AFRICA". That was so disappointing for me, that was actually one of the reasons why I said I do not want to do it in this way any more. I don't want to get hundreds of Europeans to South Africa; firstly, I always have to explain and to start afresh, kind of, explain that we do not use certain words or names for people, and so on, it really started there. For me, the idea was always to show European students something different, a different way to look at the world, a different look at the North and South, different cultures, but I am afraid for many it made "Africa" even more exotic. The collaboration and exchange between Austrian and South African architecture students were much better then, because they talk the same architecture language, but if it is just the local community in a rural or poor area, the perspective of the Austrian guest does not change much - the perception of the South. It is still common belief that you go somewhere, bring your design, bring your house, your technical solution and impose, instead of listening and really collaborating.

6 Marlene Wagner, "A Place under the Sun for Everyone - Basis for Planning of Inclusive Urban Development and Adequate Architecture Based on the Analysis of Formal and Nonformal Spatial Practice in the Housing Development Cosmo City, Johannesburg” (Thesis, Vienna University of Technology, 2010). 
I always believed these educational design-build projects need to offer a safe space to experiment. For some students it's just a nice opportunity to improve their CV, for others it is life changing (points to herself). The same is the case for local community members of the construction team. For many it's just a well-paid job, a very friendly environment to work in but nothing further, and for others, they stay in construction or they open up their own company where they apply their skills. So, there are very individual experiences. But for me, the South-North cooperation was not fulfilling anymore with the universities or architecture school, because they did not change their systems of delivering the building. The whole construction process is great, but it's always new European students while the local people already have a lot of knowledge which makes it really difficult to move forward.

\section{Spaces in-between and perspectives from afar}

Last but not least, we were eager to find out more about the personal experiences of our interview partners. They both travelled in-between spaces. They left their ordinary environments and searched for more knowledge and skills in different contexts. Nicholas, a Kenyan in Germany; Marlene, an Austrian in South Africa. From hindsight, how do they look back on South African and Kenyan construction sites from afar, incorporating their know-how from abroad? What lessons did they learn from people on the spot in their immediate surroundings? And, through their extensive experience and close contact with local communities, were they able to find out what people really want with regard to housing?

\section{Marlene}

That is difficult... the South African wants something different, and even the rural South African wants something different. It's so much more the local context again, that I would never ever, how could you say, make a global manual on how to build. Of course, you look at the general climate, but then you also have to look at the microclimate: it makes a difference if there is a lake, a city or woods. If it's good architecture, it takes a very close look at the context, on the user and on what people want. Of course, in the context as a European going with money to the South, it is very hard to hear what people want. I think that generally in South Africa, because of the traditional round hut and the climate, life happens a lot more outside. So, it is about the space between the buildings, something we should look at in more detail and take better care of, also in Europe - the shared public or semi-public space. Also because of our culture, and the temperature, we have cold winters, people spend much more time inside, but still it is the quality of the shared space that should receive much more attention. In South Africa, for me the number one is the 
climate; it is easier to build. I think in Austria it will soon be harder to build. If you get these extreme summers and extreme winters, you have to build something that works fine in both conditions. Besides, the family structures change, we have only single people living in bachelor flats now, we do not have the big families anymore. I am sure that is also changing in African countries. And there is also always the representative porch and fence, that's a suburban issue. That is in Lower Austria the same as in Cosmo City in Johannesburg, that you have the representative aspect.

\section{And the lessons learned?}

Uuh, that is a tough one. In general, I think what I learned from the people on the spot, my work, and from having lived in South Africa... I do not know where it comes from, from the construction site or maybe from poverty, maybe it is poverty that makes you more flexible, and more adaptive and more willing to find a quick solution, improvisation and these things. That is definitely what I have learned, how I work and how I improvise now. There is anyway not the one right way of doing things. . maybe that also comes from the very informal context as much as from the construction site, that there is not one procedure, there is ten different ones, so nobody will even tell you, do this. In Austria, maybe you have a plan B, but in general we have, this is the only way and bureaucracy, and as long as you do this and bring this, it will work out somehow finally. This is not the case in South Africa, there is no safety net, it can always change, you always have ten different plans, and you improvise you negotiate, and you balance. We will have to look at these skills much more here.

\section{Nicholas}

In Kenya, just like in Germany, engineers do place great emphasis on administering so-called watertight contracts that legally bind the parties involved in realizing the project. Such contracts work on a strict reward-and-sanction basis. It is my view that the parties to a contract need to agree about what is to be constructed, and have the agreement documented. This agreement should then serve them as a guide during project execution. However, overreliance on watertight contracts represents, for me, a tendency among engineers to place trust on fixed structures to regulate the construction undertaking. At times I have the impression that engineers assign the construction contract the role of autopilot for the infrastructure project. When this becomes the case a construction contract becomes a kind of formula, like the many I memorized in college, only that this version of formula contains many clauses and legal jargon. From my experience, conflicts on the construction 
site are far from being banished by cleverly formulated contracts. I have been on sites where project participants successfully realized projects despite the construction work being administered by contracts with loopholes. In the same vein, I have been engaged in projects with watertight contracts, having minimal gray areas, if any, yet these same projects were often interrupted by court injunctions. In between these diametrically opposed outcomes on site, I am learning that project realization is dependent on the commitment of those involved to cultivate and practice a culture that preserves the life of the construction project. Whenever I image culture, I see people. The human element is at the core of every project. The success or failure of the project depends on the culture that the project participants involved choose to practice, regardless of the country in which they are executing the project. I imagine that this observation would apply for housing projects, too.

And the lessons learned?

A game changer for me has been nurturing an awareness of the construction project as a living entity. The project has life because of all the people who take part in it, actively or passively. All the persons who effect or are affected by the project breathe life into it. The project first lives in the human mind and is then birthed on the construction site. The state of a construction project reflects the prevailing relations among all persons involved, the project initiators and the intended beneficiaries. Engineers can erect the most robust houses possible, but only when the needs of the dwellers are addressed will the houses be transformed into homes that shelter. Formulas are all good and have their place in the engineer's life; however, we cannot talk with numbers. Numbers can only tell us so much. We as engineers need to develop an awareness for social competences to complement the technical ones that our training endowed us with. It is time to mindfully look around us and begin talking with other project participants who represent other disciplines. I imagine a better life for construction projects if we all work together.

We wish to express our deep gratitude to Marlene Wagner and Nicholas Sungura for their openness and willingness to share their professional experiences with us.

\section{References}

Hay, Allison, and Richard Harris. “'Shauri Ya Sera Kali’: The Colonial Regime of Urban Housing in Kenya." Urban History 34 (2007): 504-530. 
Lea, Tess, and Paul Pholeros. "This is Not a Pipe: The Treacheries of Indigenous Housing." Public Culture 22 (2010): 187-209.

Sungura, Nicholas. "Der Faktor Mensch bei der Risikosteuerung öffentlicher Bauvorhaben in Kenia." Translated: "The Human Element in the Risk Management of Public Infrastructure Projects in Kenya." Unpublished Dr. Eng. diss., University of Hannover, 2016.

Wagner, Marlene. "A Place under the Sun for Everyone - Basis for Planning of Integrative Urban Development and Appropriate Architecture through the Analysis of Formal and Non-formal spatial practice in the Housing Area Cosmo City, Johannesburg." Unpublished thesis, Vienna University of Technology, 2010. 